\title{
DESAFIOS DE UMA INSTITUIC̃̃̃O PÚBLICA MUNICIPAL NA INSTITUCIONALIZAÇÃO E EXPANSÃO DO PROGRAMA DE EDUCAÇÃO A DISTANCIA
}

TAUBATÉ/SP MAIO/2018

\author{
Juliana Marcondes Bussolotti - Unitau - julianabussolotti@gmail.com \\ Patrícia Ortiz Monteiro - Unitau - patricia@epts.com.br \\ Marcia Oliveira - Unitau - oliveira.marcia@unitau.com.br \\ Rozemara Cabral Mendes de Carvalho - Unitau - rozemara@ead.unitau.com.br \\ Sanmya Feitosa Tajra - Unitau - sanmya@epts.com.br \\ Rosana Giovanni Pires - Unitau - rosanagiovanni.pires@gmail.com
}

Tipo: Relato de Experiência Inovadora (EI)

Categoria: Estratégias e Políticas

Setor Educacional: EDUCAÇÃO SUPERIOR

RESUMO

O presente artigo visa apresentar o processo de expansão de cursos e de polos de apoio presencial utilizado por uma instituição pública de ensino superior tendo como referência as fases do ciclo de vida organizacional, de forma que a cada momento, novas estratégias são utilizadas visando minimizar a tendência natural da entropia institucional. Para manter a continuidade desse desenvolvimento de forma sistematizada, a instituição optou por elaborar um Planejamento Estratégico, tendo como referência metodológica o Balanced Scorecard (BSC). Para contextualizar o entendimento desse processo, este artigo apresenta a caracterização da Universidade e os passos seguidos no crescimento organizacional.

Palavras-chave: EAD. Planejamento Estratégico. Balanced Scorecard. Ciclo de Vida das Organizações.

\section{AGRADECIMENTOS}

A PRESENTE PESQUISA FAZ PARTE DAS ATIVIDADES DESENVOLVIDAS PELO NÚCLEO DE ESTUDOS E PESQUISAS INTERDISCIPLINARES EM SABERES E PRÁTICAS EM EDUCAÇÃO À DISTÂNCIA DO NEAD/UNIVERSIDADE DE TAUBATÉ. 


\section{Introdução}

O recente crescimento da EAD no Brasil tem estimulado a reflexão sobre as bases e os caminhos pelos quais esta modalidade de ensino vem se desenvolvendo. As instituições de ensino superior do país apresentam diferentes concepções e modelos de educação a distância, marcados por disparidades e diferenças. A grande maioria desses modelos está enquadrado no que Rumble (2003) categoriza como sistema centrado na instituição, e não parece errado supor que a cultura organizacional da instituição, na qual esse tipo de ensino está inserido, tenha reflexo direto sobre o modelo, a difusão, a produção, não apenas de materiais didáticos, mas em toda uma intrincada rede de ideias e percepções acerca do trabalho realizado dentro desse contexto, que por sua vez, impacta naquilo que é oferecido aos alunos. Torna-se necessário examinar contínua e sistematicamente a realidade institucional é imperativo, analisando os diferentes momentos da vida organizacional, sempre com vistas à melhoria na qualidade do ensino ofertado. Inspirado por esta premissa, este artigo tem como finalidade apresentar o modelo e descrever os desafios observados no processo de expansão de um Programa de Educação a Distância de uma Universidade Pública, bem como seus efeitos no cotidiano e nas relações que compõem o contexto institucional analisado.

O presente relato diz respeito ao Programa de Educação a Distância de uma Universidade Pública localizada na Região Metropolitana do Vale do Paraíba paulista. A IES é uma Autarquia Municipal de Regime Especial, possui autonomia financeira, administrativa e pedagógica, e tem como missão a integração do ensino, pesquisa e extensão universitária, por meio do desenvolvimento, difusão e produção científica em três áreas do conhecimento: biociências, exatas e humanas. É um centro formador, disseminador, sistematizador e produtor do conhecimento promovendo a formação geral do futuro profissional com base numa concepção democrática. A IES tem tradicionalmente forte atuação junto à comunidade municipal e regional, caracterizada pelo ensino de graduação, de pós-graduação e de atividades de pesquisa e de extensão.

\section{As fases do ciclo de vida organizacional da EAD no contexto institucional}

As fases do ciclo de vida do Programa EAD desta IES são descritos conforme relato a seguir e podem ser compreendidos a partir do entendimento da superação das crises identificadas em cada fase organizacional, como previsto por Adizes (1996). Em cada fase do ciclo de vida, a organização lida com diferentes crises, cabendo a alta direção desenvolver em conjunto com a equipe, estratégias para minimizar os impactos posicionando-a num novo momento organizacional (IDEM, 1996). Em 2004, a IES criou 
internamente o Núcleo de Educação a Distância (NEAD), por meio de Deliberação de seu Conselho de Ensino e Pesquisa, inicialmente vinculado à reitoria. Em 2009, a Universidade obteve o credenciamento do Ministério da Educação (MEC), para a oferta de cursos na modalidade a distância, juntamente com a solicitação de autorização para oferecimento do Curso de Pedagogia. Nessa ocasião também foram credenciados os primeiros polos de apoio presencial da IES, localizados em: Taubaté, São José dos Campos-SP, Ubatuba-SP, Mogi Guaçu-SP e Belém-PA. Apesar da Instituição ter um polo de apoio presencial credenciado fora do estado de SP, optou-se por centrar esforços, na consolidação dessa modalidade de ensino dentro da Instituição, e na estruturação de dois polos próprios - o da sede em Taubaté-SP e o do município de Ubatuba-SP - e de um polo com parceiro privado, em São José dos Campos-SP. Nesseano, a Universidade ofereceu seu primeiro curso na modalidade EAD, em Ubatuba, em parceria com a Prefeitura Municipal.

Em 2012, o NEAD foi vinculado à Pró-reitoria de Graduação (PRG), sendo criada uma Coordenação de Educação a Distância para o gerenciamento da EAD, organizando um conjunto de ações relacionadas ao planejamento, desenvolvimento e implantação de cursos na modalidade a distância, sob a supervisão desta reitoria. Ainda em 2012, a Universidade iniciou os processos de reconhecimentos dos cursos oferecidos na modalidade a distância junto ao Ministério da Educação, uma vez que o Conselho Estadual de Educação (CEE) não tinha diretrizes claras para esta modalidade de ensino. Em face da sua autonomia universitária, a IES criou ao longo de nove anos (2009-2017) trinta e três cursos superiores na modalidade a distância. A partir de 2014, os cursos da EAD-UNITAU passaram a ser regulados não só pelo Ministério da Educação (MEC), mas também pelo Conselho Estadual de Educação (CEE-SP). Em 2017, o Núcleo de Educação a Distância (NEAD) da Universidade teve seu regimento próprio instituído, e recentemente, obteve seu recredenciamento por 8 anos. A partir deste percurso é possível perceber que entre os anos de 2004 e 2009, a instituição percorreu as fases do ciclo de vida das organizações conhecidos como: namoro, infância, toca-toca, tendo como principais desafios o estabelecimento dos produtos no mercado, a institucionalização do Programa de EAD na Universidade e a definição dos primeiros modelos de fluxos de trabalhos acadêmicos, administrativos, financeiros. Entre os anos de 2009 a 2014, a Programa de EAD, teve como foco promover a expansão de cursos, a implantação de sistemas administrativos e acadêmicos por meio de um sistema de informação gerencial integrado, permitindo a consolidação dos dados acadêmicos com a plataforma educacional Moodle, além de efetivar experiências com Polos presenciais próprios. Esse percurso pode ser identificado como a transição da fase toca-toca para a fase da adolescência, momento em que a instituição já identifica uma consolidação das ações realizadas e planeja a expansão externa com a constituição de parcerias. 
As atividades realizadas entre os anos de 2014 a 2017 podem ser classificadas como os momentos de transição entre a adolescência e a plenitude da empresa. A instituição teve um ganho de aprendizagem com as experiências com os polos próprios, além de todo o conhecimento constituído nos anos anteriores, o que permitiu o ingresso à nova fase organizacional. Agora, com uma gestão já baseada em técnicas e métodos gerenciais com o apoio de uma equipe mais qualificada nas dimensões pedagógica, acadêmica, tecnológica e estrutural. A busca e manutenção da fase da plenitude, considerada por Adizes (1996) como um momento muito desejado, é a fase em que a instituição pode demonstrar sua solidez interna, estruturando-se em controle sobre os processos realizados e a cultura organizacional flexível e empreendedora possibilitando mudanças contínuas para o aprimoramento das atividades realizadas, A seguir serão apresentados com maiores detalhes os principais marcos deste momento de crescimento organizacional pelo qual esta IES vem passando.

O processo organizacional do Programa de Educação a Distância desta IES, vem consolidando-se nas dimensões: pedagógica, acadêmica, tecnológica e estrutural, demonstra o sucesso na superação de obstáculos, sempre posicionando-o numa nova fase e com um melhor desempenho organizacional. Tal constatação pode ser observada pela expansão das atividades do Programa, estruturadas e sistematizadas, tais como: dimensão pedagógica: reúne o conjunto de princípios, métodos, técnicas e estratégias de ensino, a fim de garantir ao aluno o desenvolvimento e o acompanhamento eficiente e eficaz das diversas atividades de ensino relacionadas ao curso em que está matriculado.

$\mathrm{Na}$ dimensão pedagógica se dá a criação de cursos, as alterações de matrizes curriculares, e o reconhecimento e renovação de reconhecimento dos mesmos; dimensão acadêmica: compete à dimensão acadêmica, o planejamento, a organização, a coordenação e o controle de todos os procedimentos, processos e documentos referentes ao percurso acadêmico do aluno ao longo do seu período de formação universitária; dimensão tecnológica: refere-se aos procedimentos ligados à infraestrutura tecnológica e inovação para a operacionalização das demais dimensões; tem como responsabilidade o planejamento e gerenciamento da totalidade de aparatos tecnológicos necessários ao bom funcionamento da EAD; dimensão Estrutural: compreende a forma como as atividades são divididas, organizadas e coordenadas, além dos recursos necessários ao cumprimento de cada etapa relacionada a esse processo, em conformidade com os objetivos do Núcleo de Educação a Distância. A modalidade a distância permite a definição de vários modelos de desenvolvimento dos processos de ensino e aprendizagem, sendo flexível no que diz respeito à adaptação da oferta de cursos à demanda de diferentes regiões e/ou das características das 
instituições e de seus polos (ARAÚJO JR. e SOUZA, 2016).

O eixo pedagógico adotado pelo NEAD apoia-se nas metodologias ativas, colaborativas e interativas, fundamentadas nas Diretrizes Curriculares Nacionais do Curso e da Formação dos Professores, por entender que o modelo permite o melhor atendimento da diversidade contida na realidade do ensino a distância brasileiro. Os cursos de graduação, licenciaturas, bacharelados e cursos superiores de tecnologia na modalidade a distância são desenvolvidos na IES com a preocupação do redimensionamento dos espaços e tempos educacionais, considerando atividades na plataforma educacional e atividades presenciais.

A gestão pedagógica do Programa do Núcleo de EAD é realizada na sede da Instituição e os cursos estão articulados pelas áreas os quais estão vinculados, contam com uma equipe multidisciplinar formada pelos Coordenadores de Área e de Curso (sede), docentes de apoio (sede) e tutores a distância (home office). A discussão pedagógica dos cursos se dá no âmbito dos Núcleos Docentes Estruturantes (NDE's). As atividades na plataforma educacional são realizadas em salas virtuais desenvolvidas por docentes qualificados na área de conhecimento do curso e na educação a distância para aprofundamento, enriquecimento curricular e sistematização do conhecimento com o acompanhamento do tutor on line, por meio de atividades síncronas e assíncronas.

Como eixo central da abordagem metodológica adotada pelo Programa para os cursos de licenciatura, figuram os Projetos Integradores visando contribuir com a Formação Inicial do Docente para o exercício do magistério na Educação Básica proporcionando experiências significativas para a construção de referenciais teórico-metodológicos específicos de cada área de conhecimento e da docência favorecendo a inserção do aluno na realidade social e no contexto profissional da área de formação, vinculando-a à própria missão da Universidade: a indissociabilidade entre ensino, pesquisa e extensão. As atividades propostas consideram o aluno como sujeito ativo, que constrói seu conhecimento a partir da reflexão e da ação empreendida na plataforma educacional por meio da interação com as atividades propostas, com seus colegas de turma e com os tutores.

Articuladas a esta proposta encontram-se as Atividades Complementares, especificamente nas licenciaturas denominadas Atividades Teórico-Práticas de Aprofundamento (ATPA). Estas se estruturam por meio da realização de oficinas sobre temáticas inclusivas e emergentes, como: políticas de inclusão e acessibilidade, diversidades étnico-raciais e de gênero e educação ambiental para a sustentabilidade, que consideram a implantação de escolas sustentáveis e resilientes, além da realização 
de Atividades Científicas e Culturais e de formação geral contemporânea. Quanto aos Cursos Superiores de Tecnologia e Bacharelados, as Atividades Complementares (AC) caracterizam-se como atividades paralelas ao curso, de aprofundamento e diversificação de estudos, que possibilitam o reconhecimento de habilidades e competências do aluno fora do ambiente escolar. Espera-se que a totalidade dessas diferentes atividades desenvolvam nos alunos as competências necessárias ao exercício da profissão.

Apesar de ser uma Universidade Pública, cobra-se mensalidade dos alunos para sua sustentabilidade, uma vez que a IES não recebe subsídios financeiros do município, estado ou federação. Tal entendimento posiciona os Gestores desta IES quanto à necessidade no desenvolvimento do espírito empreendedor como uma forma de promover a gestão institucional. Diante dessa realidade a IES tem interesse em consolidar e expandir o seu Programa de Educação a Distância, pois representa uma possibilidade de crescimento em número de alunos e abertura de novos mercados, bem como permite exercer sua função social, de democratização da educação. Para esse fim, estabeleceu parceria com uma Empresa Pública da própria Universidade em outubro de 2013. As duas instituições celebraram um Convênio de Cooperação para realização de projetos de natureza Pedagógico-Técnico-Científica. O referido convênio, visa à oferta de cursos de graduação na modalidade a distância, fixando as responsabilidades de cada parceiro.

Em síntese, a parceria atribuiu à Empresa a gestão administrativa e financeira dos cursos de graduação a distância e do plano de expansão dos polos de apoio presencial do Programa de Graduação a Distância, responsabilizando-se assim pelo planejamento estratégico das ações pertinentes ao Programa de Expansão, bem como por todo o processo de arrecadação, custeio e planejamento dos investimentos necessários à sua manutenção, inclusive aplicando recursos financeiros próprios, para custeio de eventuais adequações que os polos necessitem, no que tange às suas instalações físicas, especialmente em relação à biblioteca (acervo digital), à infraestrutura de tecnologia de informação e comunicação, aos recursos humanos e materiais pedagógicos, e às ações de comunicação e marketing.

Em 2014 a Empresa trabalhou na estruturação deste Convênio dando suporte ao Programa de Educação a Distância, e iniciou, timidamente, a expansão de polos da EAD. No ano de 2015 e no primeiro semestre de 2016, por meio da divulgação pública da expansão do Programa NEAD da IES, no site da Empresa e do preenchimento de uma ficha de interesse, foram cadastrados 48 (quarenta e oito) polos de apoio presencial na plataforma E-mec, em demanda espontânea de parceiros que procuraram o Programa do Núcleo de Educação a Distância da IES e que cumpriam os critérios de 
infraestrutura e documentação exigidas na legislação MEC/INEP. Estudou-se os cenários locais dos polos de apoio presencial cadastrados por revisão documental e visitas in loco por meio da então recém-criada Coordenação de Expansão de Polos, para verificação da infraestrutura e da documentação mais detalhada exigida, e preparação para as visitas do MEC/INEP com vistas ao credenciamento desses locais, que de forma geral aconteceram no intervalo de 2 a 3 anos. Uma vez realizadas essas visitas, os Polos ou parceiros que não atendiam todas as especificações mínimas do instrumento do INEP para o seu reconhecimento ou de documentação exigida pela Empresa, foram instruídos a realizar as adaptações necessárias. Os parceiros que não fizeram as adequações de infraestrutura e documentação foram desligados do Programa em 2017. Outros desses parceiros desistiram pela morosidade do processo de credenciamento dos polos pelo órgão regulador e pela persistência do Programa de Educação a Distância em cumprir rigorosamente a legislação.

Vale ressaltar que até junho de 2017, a referida expansão caminhou a passos lentos, devido à burocracia do Ministério da Educação - MEC, que exigia para o deferimento do pedido de credenciamento do polo que estes fossem aprovados por uma comissão de avaliadores do INEP, mediante visita in loco. Ocorre que o próprio INEP não conseguia atender em um prazo de tempo razoável a demanda de pedidos de credenciamento das IES, demorando 2 a 3 anos para credenciar um polo. Essa situação mudou quando o MEC publicou a Portaria Normativa no11, de 20 de junho de 2017, que regulamentou a criação de Polos EaD pelas próprias instituições já credenciadas para esta modalidade de ensino, bem como o imediato credenciamento dos polos que já haviam recebido a referida visita. Assim, a medida permitiu a IES encerrar 2017 com 25 Polos EAD ativos, além da sua Sede, todos devidamente credenciados para a oferta de cursos de graduação a distância.

\section{O Planejamento Estratégico da EAD: um Novo Passo para o Alinhamento das Ações Desenvolvidas}

Como forma de sistematizar a expansão das atividades da EAD recorreu-se à elaboração do Planejamento Estratégico contando com a participação de profissionais da Empresa e da IES de diferentes áreas (pedagógica, administrativa, jurídica, comunicação, comercial e de tecnologia da informação), o que possibilitou uma maior integração da equipe e uma produção interdisciplinar e intersetorial. As reuniões foram conduzidas por meio da técnica do brainstorming e as decisões tomadas por consenso entre os participantes: em torno de 25 profissionais por reunião. Dessa forma estabeleceu-se os objetivos institucionais para realização do Planejamento Estratégico bem como as perguntas norteadoras para traçar os temas emergentes. Visavam a 
integração das ações da EAD; a promoção da gestão participativa; a integração de todas áreas; a contribuição para o novo ciclo da expansão; a sensibilização da equipe para o entendimento da dimensão da EAD; a sistematização do processo de acompanhamento de resultados; o desenvolvimento de ações para atingir a qualidade desejada; uma adequação interna para um novo modelo de acolhimento dos novos colaboradores, alunos e parceiros. Esses objetivos estratégicos foram considerados essenciais para um novo posicionamento da EAD, constituindo sua vantagem competitiva (PORTER, 1992)

A metodologia utilizada para a estruturação e acompanhamento do Planejamento Estratégico foi o Balanced Scorecard (BSC) (Kaplan e Norton, 1997), que considera essencial a constituição de um conjunto de ações e indicadores para o monitoramento do desempenho global de uma instituição. O BSC é constituído por duas ferramentas: 0 mapa estratégico que demonstra de forma gráfica a inter-relação entre as estratégias e o conjunto de indicadores, que compõem o painel de controle para apoio no monitoramento dos resultados planejados.A produção do Planejamento Estratégico da EAD, teve como referência um prazo de 5 (cinco) anos e foi composto com os seguintes elementos: definição de negócio, missão, visão, valores, política de tomada de decisão, diagnóstico organizacional (SWOT), macro objetivos estratégicos, estratégias e planos de ação. Cada estratégia foi definida com um objetivo que subsidia a definição de uma meta. A partir desta produção, a IES/Empresa passou a promover reuniões mensais para acompanhamento do desenvolvimento das ações previstas no Plano de Ação e efetuar possíveis ajustes de acordo com as ocorrências no meio interno e/ou externo.

Protagonizando um novo modelo, a partir de Planos de Ação integrados, espera-se cumprir as metas estabelecidas, constituindo uma rede de polos ao longo dos próximos 5 anos (2018-2022), promovendo a democratização do acesso ao ensino superior a distância, com base na extensa experiência acadêmica acumulada ao longo da história da universidade, que resultará em uma marca forte e valorizada em todo território brasileiro.

O marco legal da Educação a Distância pode ser dividido em dois momentos: antes do Decreto $n^{\circ}$ 9.057/2017, onde as IES eram dependentes de procedimentos burocráticos de análise documental e vistorias presenciais do MEC/INEP para terem seus polos credenciados, processos estes que levavam em torno de 24 meses para serem concluídos; e após o decreto, quando o processo foi flexibilizado e as IES autorizadas a criarem novos polos por ato próprio, respeitando limites quantitativos definidos pelo próprio MEC, com base nas avaliações institucionais. É sabido que tais decisões foram politicamente tomadas para que o MEC atinja a Meta 12 do Plano Nacional de Educação 
(PNE), que exige elevar a taxa bruta de matrícula na educação superior em $50 \%$ e a líquida em 33\% da população entre 18 e 24 anos. Porém, é perceptível o consequente aumento da concorrência qualificada e desqualificada na oferta de cursos a distância. Nessa esteira, a concorrência tornou-se mais agressiva, abrindo polos por todo o país, e oferecendo cursos com baixo preço e duvidosa qualidade. A explosão no número de instituições oferecendo graduação a distância e as restrições ao Financiamento Estudantil (FIES) deflagraram uma guerra tarifária entre as instituições privadas, constituindo o que os autores Kim e Mauborgne (2015) chamam de mar vermelho, em que a base da concorrência é o preço, levando às organizações a um mercado comoditizado e cada vez mais difícil de competir por não haver uma diferenciação clara na oferta dos serviços.

A sede do Programa do NEAD está localizada no Vale do Paraíba, com 14 IES concorrentes oferecendo cursos presenciais e a distância. Entretanto, a IES e a empresa que promove a operacionalização do Programa não possuem recursos financeiros para uma expansão rápida e agressiva no mercado, e tão pouco a mesma flexibilidade para estabelecer parcerias quando comparada os concorrentes privados do setor, pois não tem a mesma agilidade nas negociações e possibilidade de pagar comissões ou bonificações aos parceiros como praticado no mercado. Vale ressaltar também que a Empresa sempre prezou pelo nome da IES e, por isso, busca parcerias que também entendam e respeitem e sua tradição, adquiridos em mais de 60 anos de existência. Entende-se que com campanhas de comunicação e de marketing, projetos de novos de cursos, ampliação de Polos, ampliação de equipe comercial, a incorporação de inovações tecnológicas constantemente e ajustes no setor de produção de materiais em função das novas matrizes curriculares dos cursos, será possível realizar a expansão de forma estruturada conforme o planejado e sempre preservando a sustentabilidade organizacional. Embora muitos obstáculos de relacionamento entre as equipes e a interação dos cursos do Programa de Graduação a Distância e as Unidades Departamentais do ensino presencial da IES já tenham sido superados ao longo dos últimos anos, ainda existem algumas resistências no âmbito da comunidade acadêmica da Universidade, das seguintes ordens: receio de parte dos professores de que alunos dos cursos presenciais se transfiram para os cursos a distância; morosidade na ampliação de polos EAD e cursos a distância na região metropolitana do Vale do Paraíba, pelo mesmo motivo acima citado; ainda há um grande desconhecimento dessa modalidade de ensino, faltando formação e vivências significativas em EAD para compreender as diferenças duas modalidades; crença de que é a modalidade de ensino que determina a qualidade da educação. Como apontado por Robbins (2005) a mudança organizacional e a incorporação de novas formas trabalho são afetadas positivamente e negativamente pela cultura das organizações, cabendo aos gestores 
estarem atentos aos fatores internos e externos para realizar as adequações que favoreçam a sustentabilidade institucional.

\section{Considerações Finais}

Entende-se, com a trajetória apresentada, que os novos momentos institucionais serão favorecidos pela aprendizagem organizacional obtida ao longo de cada fase do desenvolvimento da IES, entretanto, para que o Programa de EAD mantenha-se vivo, sempre será necessário manter a equipe disponível e preparada para lidar com as mudanças contínuas seja em relação aos aspectos estruturais, tecnológicos, pedagógicos e administrativos, evitando que o processo de entropia organizacional se consolide. Alinhar as expectativas internas de uma cultura organizacional de uma universidade pública e as do mercado externo será, por um longo prazo, um dos maiores estímulos para os gestores deste Programa

\section{REFERÊNCIAS}

ADIZES, I. O Ciclo de Vida das Organizações. 3a. edição. São Paulo: Pioneira, 1996.

ARAÚJO Jr. C.F., SOUZA, A. M. Métodos Institucionais de Educação a Distância. Desafios da Educação a Distância: inovação e institucionalização. São Paulo: Terracota, 2016.

RUMBLE, G. A gestão dos sistemas de ensino a Distância. Brasília, DF: UNB, 2003.

KAPLAN R. e NORTON. A estratégia em ação. Balanced Scorecard. Rio de Janeiro: Elsevier, 1997.

KIM, W. C. e MAUBORGNE, R. A estratégia do oceano azul. Rio de Janeiro, Sextante: 2015.

ROBBINS, S. P. Comportamento Organizacional. São Paulo: Pearson Educacional, 2005.

PORTER, V. Vantagem competitiva: criando e sustentando um desempenho superior. Rio de Janeiro: Campus, 1992. Disponível em: www1.folha.uol.com.br. Acesso em: 20 mar. 2018. 